\title{
LA CONCEPCIÓN CRISTIANA DEL TRABAJO EN LA EVOLUCIÓN LEGISLATIVA NACIONAL (Y EN ESPECIAL SOBRE
} LA PROTECCIÓN DE LA PERSONA DEL TRABAJADOR)

\author{
Eduardo Jequier Lehuedé ${ }^{1}$
}

RESUMEN: El autor a través de este trabajo pretende explicar cómo ba sido la regulación jurídica de la protección al trabajador en la legislación chilena. Para erllo pasa revista a las tendencias económicas a este respecto y las vincula con las revisiones y ejemplos derivados de la Doctrina Social de la Iglesia Católica que constituye la concepción cristiana del trabajo.

Palabras Clave: Trabajo - Concepción cristiana - Legislación laboral.

ABSTRACT: The author intends to explain in this essay what the juridical regulation has been towards the protection of workers in the Chilean legislation. He reviews the economical trends in this regard and links them with the revisions and examples derived from the social doctrine of the Catbolic Church that represents the Christian conception of labor.

KEY wORDS: Labor - Christian conception - Labor legislation.

SUMARIO: Introducción. I. Algunos aspectos de la protección del trabajador en la legislación chilena; la concepción cristiana y la economía de mercado. A) Los accidentes del trabajo y las enfermedades profesionales. B) Servicio de Seguro Social y Servicio Nacional de Salud. C) El "sábado inglés". D) El descanso dominical y en días feriados. E) Las sillas en los establecimientos comerciales e industriales. F) El peso de los sacos de carguío por fuerza de hombre. II. Conclusiones. Bibliografía.

\section{INTRODUCCIÓN}

Desde RERUM NOVARUM (1891), del Papa León XIII, hasta LABOREM EXERSENS (1981), del Papa Juan Pablo II, la Doctrina Social

Abogado. Magíster en Derecho de la Empresa, Pontificia Universidad Católica de Chile. Profesor de Derecho Económico y de Derecho Comercial, Universidad Católica del Norte, Coquimbo. Correo electrónico: ejequier@ucn.cl

Artículo recibido el 11 de enero de 2005. Aprobado por el Comité Editorial el 17 de noviembre de 2005 . 
de la Iglesia Católica se ha ocupado muy especialmente del trabajo humano como expresión esencial del hombre, en cuanto ser personal. León XIII, durante su pontificado, dio especial importancia al desarrollo o difusión de la concepción cristiana del trabajo, para distinguirla de aquella visión rígida y puramente instrumental del liberalismo (o del capitalismo como su expresión económica), en donde el trabajador no era más que una simple mercancía, por cierto reemplazable, cuyo valor se determinaba por el solo juego del mercado. Fue precisamente León XIII quien dio los primeros pasos hacia un principio fundamental que informaría luego el pensamiento social de la iglesia, al señalar en "Rerum Novarum" que, antes que todo, existía una justicia superior a la mera justicia conmutativa que ofrecía el liberalismo. A partir de dicho pensamiento, la encíclica Quadragesimo Anno (1931), de Pío XI, se ocupó de reivindicar el verdadero concepto cristiano del trabajo, rescatando por fin "a la persona" del trabajador, como ente subjetivo, por sobre el resultado puramente material de su trabajo. Se habló, pues, de "justicia social", para remecer de algún modo la conciencia de quienes detentan el poder político y económico en las diversas sociedades. "Dar a cada uno lo que le corresponde en materia de bienes y servicios societales", dijo Pío XI en su encíclica, agregando que "el Estado y las instituciones sociales deben hacer lo que les corresponde para lograr el bien común", y que "es la caridad la que debe inspirar la actividad económica".

Sin embargo, es en Laborem Exersens en donde, después de 100 años de haberse escrito Rerum Novarum, se reconocen los profundos cambios que ha experimentado la sociedad y el hombre contemporáneo para descubrir, a partir de esa nueva realidad, "los nuevos significados del trabajo humano". Juan Pablo II da al trabajo humano el carácter de "clave" para la comprensión de la cuestión social, destacando en todo momento que, ya desde el libro del Génesis, el Evangelio nos enseña que el trabajo "constituye una dimensión fundamental de la existencia humana sobre la tierra". Sin embargo, a lo largo de toda su encíclica el Papa nos advierte, en forma casi reiterativa, que es el trabajo el que está en función del hombre, y no el hombre en función del trabajo. Si bien los diversos trabajos realizados por los hombres tienen distintos valores objetivos, nos insiste Juan Pablo II en que esos distintos trabajos se deben medir, ante todo, "con el metro de la dignidad del sujeto mismo del trabajo, o sea de la persona, del hombre que lo realiza".

Tal vez si las palabras más elocuentes de Laborem Exercens, que a fin de cuentas han motivado el presente trabajo, son aquellas en que se refiere a la dignidad del trabajo humano, en cuanto parte esencial de la propia humanidad. Allí, señala el Papa:

"El trabajo es un bien del hombre -es un bien de su bumanidad-, porque mediante el trabajo el hombre no solo transforma la naturaleza 
adaptándola a las propias necesidades, sino que se realiza a sí mismo como hombre, es más, en cierto sentido se hace más hombre"2.

Precisamente entonces, es a partir de esta concepción cristiana del trabajo que trataremos de abordar, desde una perspectiva de análisis histórico de su evolución legislativa, un aspecto determinado del trabajo humano en nuestro país; esto es: La protección del trabajador en la ley chilena (cuestión directamente ligada con la dignidad del trabajo y la importancia del sujeto por sobre sus resultados materiales).

Cabe representar, en todo caso, que el presente ensayo no encierra más ambición que mostrar, en forma muy sintética y a partir de dos aspectos concretos, cómo ha reaccionado nuestra legislación laboral ante la enseñanza de la Doctrina Social de la Iglesia, por una parte, y ante el influjo -por la otra- de las nuevas tendencias y concepciones económicas introducidas al país en la década de los setenta y, con más fuerza, en los años ochenta. El tema, por cierto, daría para un estudio extenso y acabado que, dadas las características del presente trabajo, no pretendemos emprender aquí.

\section{Algunos aspectos de la protección del trabajador en la LEGISLACIÓN CHILENA; LA CONCEPCIÓN CRISTIANA Y LA ECONOMÍA DE MERCADO}

$\mathrm{Si}$ analizamos las diversas construcciones legislativas que han nacido a la vida jurídica en este siglo, para confrontarlas luego con la concepción cristiana del trabajo humano y la dignidad y primacía del sujeto de trabajo, no podemos dejar de reconocer los esfuerzos que el legislador ha hecho para incorporar, como elemento esencial del trabajo humano, el reconocimiento de la dignidad mínima que debe asegurarse al trabajador, como "sujeto eficiente" del proceso productivo.

Una rápida mirada a algunas de las múltiples creaciones legislativas de este siglo, tendientes a proteger al trabajador y a dignificar su trabajo, nos lleva a reconocer que todas ellas (con alguna excepción que se nos escapa), fueron concebidas, precisamente, a comienzos y mediados del presente siglo. Muchas de esas instituciones jurídicas, inspiradas tal vez en Rerum Novarum o Quadragesimo Anno, buscaron aliviar la insostenible situación en que se encontraban los trabajadores a fines de siglo XIX y principios del siglo XX, sumidos en un sistema que Juan Pablo II denomina "economista", en donde lo espiritual y personal (la

2 Laborem Exercens; I,9. 
acción del hombre, los valores morales y similares) están situados en una posición subordinada a la realidad material o, a fin de cuentas, al materialismo práctico.

Veremos entonces algunos ejemplos concretos de lo que hemos adelantado más arriba:

\section{A) Los accidentes del trabajo y las enfermedades profesionales}

Si bien en todos los tiempos ha habido una preocupación constante de parte de los legisladores y estadistas responsables con respecto a la suerte de los obreros y empleados, víctimas de un accidente del trabajo y de la de sus familias, ha sido solo en la década de los años cuarenta que en Chile se tomó verdadera conciencia de la importancia social de regular especialmente esta materia, distinguiéndola de las instituciones tradicionales del derecho civil para constituir, a partir de la sistematización de sus conflictos propios y específicos, una nueva rama dogmática.

Durante el siglo XIX, al trabajador accidentado en su trabajo no le quedaba más alternativa que recurrir por la vía de las normas comunes del derecho civil, sobre responsabilidad extracontractual, lo que implicaba la necesidad de recurrir a los tribunales de justicia para establecer, en un juicio demoroso y de por sí engorroso para el trabajador, la responsabilidad del empleador. En este esquema, entonces, la responsabilidad del empleador era solo teórica, ya que para que prosperara la acción los trabajadores debían acreditar: 1) la existencia del contrato de trabajo; 2) que el obrero o empleado había sufrido un accidente; 3) que este había ocurrido como consecuencia del trabajo realizado; y 4) que el accidente era debido a culpa del patrono o, por ejemplo, que el empleador conscientemente utilizaba maquinaria defectuosa o la había instalado con ligereza, lo que implicaba una prueba imposible ${ }^{3}$.

Este régimen, que imperó durante casi todo el siglo XIX y que en el hecho dejaba a los obreros que sufrían accidentes del trabajo sin defensa alguna, fue substituido por otros más moderados. Diversos fueron los intentos en este sentido. Así, tal vez la primera expresión de la nueva tendencia, antecesora al establecimiento del riesgo profesional, fue la ley prusiana de 3 de noviembre de 1853 , que imponía a las empresas ferroviarias la obligación de reparar los daños que causaran a consecuencia de su actividad, sin discriminar acerca de si la víctima fuera un trabajador, un pasajero o un tercero ajeno al servicio.

De la Cueva, Mario: "Derecho Mexicano del Trabajo”, Ed. Porrúa, México, 1961, T. II, pág. 39. 
Más tarde, el 7 de junio de 1871 , se dictó la ley de Responsabilidad Civil del Imperio Alemán, que daba lugar a una responsabilidad de indemnización por el ejercicio de una industria que, aunque legítimo, determinase un riego considerable para los demás. En otros términos, se sentó aquí el principio de que una industria peligrosa no debe explotarse a riesgo de sus trabajadores ${ }^{4}$.

Por último, se impuso la teoría del riesgo profesional, también llamada "riesgo creado" y "riesgo de explotación", según la cual el patrón o empleador es responsable de los accidentes del trabajo ocurridos a sus obreros y empleados, exceptuándose solo los casos debidos a fuerza mayor y sin relación alguna con el trabajo, y los producidos intencionalmente por la víctima, excepciones cuya prueba corresponde al patrón. La particularidad de este sistema es que la indemnización que se paga a las víctimas de accidentes de trabajo, o a sus representantes, está determinada por la ley con anterioridad a la ocurrencia, la que no exige que se investigue la causa de aquellos. Sin embargo, esta teoría fue objeto de agudas críticas por parte del empresariado, que estimaba injusto un sistema en que el deber de reparación se hacía recaer sobre un solo lado, no obstante que los daños se originarían en actividades normales que son útiles no solo "para el patrono", sino también para el trabajador y, al mismo tiempo, para la colectividad en general"s. Con el fin de evitar entonces esta "inequitativa unilateralidad" -se dijo-, debía substituirse la responsabilidad individual del patrono, desplazando el problema hacia el campo del derecho público. Debían ser las instituciones de seguridad social las encargadas de cubrir los riesgos provenientes de los accidentes del trabajo y las enfermedades profesionales, considerando especialmente que dichas entidades se financian con la colaboración de los empleados o patrones, de los trabajadores y del Estado. Se propone, en definitiva, substituir el régimen privado por otro sobre seguro obrero.

Lo anterior, pues, permite visualizar el conflicto permanente que en aquel entonces se producía entre un trabajador accidentado, con ocasión del desempeño de su trabajo, y un criterio que exigía la intervención estatal y que distinguía, claramente, entre los intereses del patrono -por un lado- y los del obrero o empleado, por el otro. Al respecto, mucho podría decirse a la luz de la enseñanza de la Doctrina Social de la Iglesia en cuanto al concepto de la propiedad y su función o destinación universal, como "derecho común de todos a usar de los bienes

4 Fermandois, Francisco Javier: "Régimen Legal del Trabajo en Chile”; Edit. Nascimento, 1965, T. II, pág. 8.

5. Krotoschin, Ernesto: "Tratado Práctico de Derecho del Trabajo"; Ed. Depalma, Buenos Aires, 1955, T. I, pág. 331. 
de la entera creación". Ciertamente, el conflicto surgido en relación con la determinación del sujeto pasivo del deber de reparar los daños por accidentes del trabajo y enfermedades profesionales (si el "patrono" o el Estado), no tuvo en cuenta -tal vez- el principio del destino universal de los bienes, del que se sigue un derecho humano fundamental, en el decir del Papa Juan Pablo II: "usar los bienes para la satisfacción de las diversas necesidades humanas". La propiedad privada se concibe solo como un medio, según enseña Laborem Exersens, entre muchos otros, que puede ser el correcto siempre y cuando todos los hombres y todos los pueblos puedan, mediante el ejercicio de la propiedad privada, usar efectivamente de los bienes para su sustento. Pero para el empleador de ese entonces, el destinar los bienes resultantes del proceso de producción, para satisfacer las necesidades del trabajador accidentado en esas mismas labores, era simplemente "injusto e inequitativo".

Lo anterior llevó a que el Estado, consciente de este problema, recomendara a los gobiernos de las naciones americanas que gestionaran, en sus respectivos países, la promulgación de leyes que implantaran el seguro social contra el riesgo de accidentes del trabajo y de enfermedades profesionales, y la organización sistematizada de su prevención ${ }^{6}$.

Hecha esta sucinta relación histórica, llegamos entonces a la dictación de la Ley $\mathrm{N}^{\circ} 16.744$, de fecha 1 de febrero de 1968 (Diario Oficial), vigente hasta el día de hoy. Esta ley vino a refundir todas aquellas dispersas en materia de accidentes del trabajo y enfermedades profesionales, sistematizándolas en un solo cuerpo. No es nuestra intención entrar al análisis de esta ley, por cuanto ello escapa al propósito de este trabajo. Unicamente diremos que dicha ley parte declarando "obligatorio" el seguro social contra riesgos de accidentes del trabajo y enfermedades profesionales (art. 1). En ella, se protege a todos los trabajadores por cuenta ajena, cualquiera que sean las labores que ejecuten, sean manuales o intelectuales, y cualquiera que sea la naturaleza de la empresa, institución, servicio o persona para quien trabajen; se protege también a los funcionarios públicos; a los estudiantes que deben ejecutar trabajos que signifiquen ingreso para el respectivo plantes; y a los trabajadores independientes. Asimismo, la afiliación de un trabajador hecha en una caja de previsión para los demás efectos de seguridad social, se entenderá hecha por el ministerio de la ley, para este seguro, a menos que el empleador respectivo esté adherido a una Mutualidad ${ }^{7}$. Se protegen

6 Primera Conferencia Interamericana de Seguridad Social", celebrada en Santiago de Chile en septiembre de 1942, en: ArIAS, José F.: "Medicina Social, Medicina del Trabajo"; Ed. Montevideo, 1949, pág. 26.

7 El Decreto $\mathrm{N}^{\mathrm{a}} 285$ del Ministerio del Trabajo y Previsión Social, publicado en el D. Of. de 26 de febrero de 1969, aprobó el estatuto orgánico de las Mutualidades de Empleadores, a que se refirió la Ley $\mathrm{N}^{\circ} 16.744$. 
los accidentes del trabajo, entendiéndose por tales toda lesión que una persona sufra a causa o con ocasión del trabajo y que le produzca incapacidad o muerte, incluyéndose aquí las que se produzcan en el trayecto directo entre la habitación y lugar de trabajo o viceversa. Por último, se protegen las enfermedades profesionales, esto es, las causadas de una manera directa por el ejercicio de la profesión o del trabajo que realice una persona y que le produzca incapacidad o muerte.

\section{B) Servicio de Seguro Social y Servicio Nacional de Salud}

La Ley $\mathrm{N}^{\circ} 10.383$, del 8 de agosto de 1953 , que modificó y reemplazó la Ley $\mathrm{N}^{\circ} 4.054$ del año 1924, se ocupó de regular el funcionamiento del Servicio de Seguro Social y del Servicio Nacional de Salud, en lo que respecta a las obligaciones para con los asegurados.

Se estableció aquí, como obligaciones del Servicio de Seguro Social (al que se le da entonces el carácter de servicio público), el otorgamiento de asignación familiar obrera; subsidio de cesantía total o parcial; indemnización por años de servicios; préstamos para la adquisición de bienes muebles; venta de casas a asegurados y pensionados; régimen de continuidad en la previsión; y pensiones de invalidez, vejez, viudez, orfandad, montepío a la madre de los hijos naturales, asistencia a inválidos $\mathrm{y}$ ancianos y de accidentes del trabajo o enfermedad profesional.

Entre las obligaciones del Servicio Nacional de Salud, se estableció la de prestar subsidio de enfermedad; subsidio de medicina preventiva; subsidio maternal; subsidio de lactancia; asistencia médica para asegurados, sus cónyuges, hijos y pensionados; tratamiento médico y quirúrgico en policlínicos, hospitales o a domicilio; asistencia pre y postnatal, hospitalizaciones; atención farmacéutica a los asegurados, pensionados e hijos; atención dental; otorgamiento de lentes ópticos; y entrega de leche y alimentos terapéuticos para la alimentación de hijos de asegurados y pensionados.

\section{C) El "sábado inglés"}

La Ley $\mathrm{N}^{\circ} 11.999$, de 31 de diciembre de 1955, reglamentada por el decreto $\mathrm{N}^{\circ} 1.987$ de Interior, de 22 de agosto de 1956, facultó a las municipalidades para que, a solicitud de empleadores o empleados, decreten el cierre obligatorio de los establecimientos comerciales minoristas los sábados a las trece horas, con excepción de los que expendan, exclusivamente, artículos alimenticios. Su artículo $2^{\circ}$ ordenó, sin perjuicio de lo anterior, que los negocios que enumera suspendan sus ventas y toda actividad de su personal los sábados después de las trece horas, en las ciudades de Antofagasta, Valparaíso, Santiago, Talca, Concepción, Talcahuano, Temuco, Valdivia, Río Bueno, Osorno, Puerto 
Montt y Punta Arenas, incluyendo las ciudades agregadas por la Ley 16.227. La índole o naturaleza comercial, según el artículo 7 del reglamento, se determinaba según la clasificación de la patente municipal y el giro del negocio. Por último, solo podían exceptuarse de las disposiciones de la Ley 11.999, los días sábados inmediatamente anteriores a las festividades patrias, de Navidad y año nuevo, considerándose como extraordinarias las horas trabajadas en esos casos.

Sin embargo, y como era de esperarse, esta ley encontró fuertes resistencias por parte de los empresarios y comerciantes, que ante todo solo miraban la disminución que aquella le imponía a sus ingresos. El descanso de los trabajadores, impuesto por esta ley, no compensaba entonces, en modo alguno, las pérdidas que para el negocio ello importaba. No digo, entiéndase bien, que comparta a ultranza el criterio introducido por esta ley; únicamente busco mostrar aquí un síntoma evidente de la ausencia casi endémica de solidaridad que ha existido siempre en el sector del trabajo, cuestión que se ha visto seriamente agudizada con la introducción, a partir de la década de los setenta, de la economía de mercado.

Asimismo, si se analiza el tenor de las críticas de que fue objeto esta ley, podemos constatar, una vez más, cómo esta ausencia de solidaridad es siempre "maquillada" de múltiples formas, lo que a fin de cuentas no es otra cosa que engañar la propia conciencia. En efecto, las críticas principales de la época no mostraron directamente el verdadero fin que ellas buscaban, en orden a que el trabajador constituía básicamente un medio del empleador para obtener mayores recursos. Muy por el contrario, tales críticas discurrieron sobre la base de que, tal iniciativa legal, era muy perjudicial para el propio trabajador y su familia. Para fundar lo anterior, baste citar dos publicaciones del diario El Mercurio de Santiago:

"El problema fundamental de las mujeres que forman parte de la clase proletaria es el de disputar cada sábado el salario a sus maridos, a fin de poder satisfacer las necesidades hogareñas antes de que esos recursos se dilapiden en la cantina o en el juego".

El mismo diario, en su editorial del 6 de mayo de 1956 (vigente ya la ley), dijo:

"Los hechos nos ban dado la razón. Mientras el comercio, particularmente el de los barrios, permanece cerrado desde mediodía del sábado hasta la mañana del lunes, se mantienen abiertas las puertas de las cantinas y las de los locales destinados al juego. Ocurre, entonces, que el obrero que acababa de recibir su salario semanal no puede invertirlo en las necesidades de su grupo familiar, aun aquellas más premiosas, pero, puede, en cambio, derrocharlo en los vicios más demoledores de la estructura y la economía de su hogar". 
En síntesis, si confrontamos el espíritu que movió al legislador de la época, por una parte, y el desprecio lamentable por el trabajo que subsistía aun en la sociedad en que dicha ley debía regir, por la otra, constatamos de inmediato que el problema de fondo, a fin de cuentas, no reside en la falta de iniciativas o instrumentos legislativos, sino en un arraigado menosprecio por la persona del trabajador y la dignidad del trabajo humano.

Son, tal vez, estas mismas expresiones sociales a las que el Papa Juan Pablo II se refiere -26 años después- en Laborem Exercens, cuando advierte que las manifestaciones nefastas del liberalismo rígido o del socialismo científico de Marx y Engels (en cuanto ambos ven al trabajador como un factor de producción) "pueden repetirse dondequiera que el hombre sea tratado de alguna manera a la par de todo el complejo de los medios materiales de producción, como un instrumento y no según la verdadera dignidad de su trabajo, o sea, como sujeto y autor y, por consiguiente, como verdadero fin de todo proceso el proceso productivo".

\section{D) El descanso dominical y en días feriados}

Los dueños, gerentes o administradores de establecimientos comerciales o industriales y otras empresas de cualquier naturaleza, pública o privada, aunque sean de enseñanza profesional o de beneficencia, deben dar a sus operarios o empleados descanso dominical y en los días feriados. En estos días, los establecimientos industriales y comerciales deben permanecer cerrados; no les es lícito atender al público ni expender artículos de su giro, y están obligados a suspender todo trabajo. El primer reglamento general sobre el descanso dominical fue aprobado por D.S. $\mathrm{N}^{\circ} 101$, de 16 de enero de 1918 , sin perjuicio del cierre del comercio en los negocios minoristas considerados en la Ley $\mathrm{N}^{\circ} 11.999$ en los lugares y ciudades ya mencionados en el párrafo precedente, y sin perjuicio de la facultad del Poder Ejecutivo para decretar el cierre obligatorio de los establecimientos comerciales en general los días sábado, después de las trece horas.

Este reconocimiento al derecho de descanso del trabajador, ha subsistido hasta nuestros días (artículos 46 a 49 del D.L. 2.200, de 1978 -hoy derogado- y artículos 35 a 40 del actual Código del Trabajo). Sin embargo, la introducción de los criterios de libre mercado a nuestro sistema económico, a partir del año 1973 (cuya consagración definitiva se encuentra en la Constitución Política de 1980), ha alterado sensiblemente, en mi concepto, el derecho de descanso a que nos referimos. En su concepción primitiva, el descanso dominical y en días feriados era la regla general y absoluta, cuyas excepciones -expresamente reguladas en el artículo 327 del Código del Trabajo de 1931- solo permitían el trabajo dominical en casos muy específicos y restringidos. Se lo permitía, 
pues, solo en faenas destinadas a reparar deterioros irrogados por fuerza mayor o casos fortuitos, siempre que la reparación fuese impostergable; en las explotaciones o labores que exijan continuidad por la índole de las necesidades que satisfacen, por motivos de carácter técnico, o por razones fundadas en la conveniencia de evitar notables perjuicios al interés público o de la industria; en las obras que por su naturaleza no pueden ejecutarse sino en estaciones determinadas y que dependen de la acción irregular de las fuerzas naturales; y en los trabajos necesarios e impostergables para la buena marcha de la empresa. Sin embargo, hoy en día basta con hacer una visita a cualquier centro comercial para constatar que el descanso dominical obligatorio es letra muerta. Ninguna objeción existiría, en todo caso, si el trabajador pudiese decidir soberanamente entre gozar de su descanso dominical u obtener, por el contrario, una mayor remuneración con su trabajo; y que tal decisión fuese respetada, solidariamente, por el empleador. Sin embargo, no podemos ser ingenuos al considerar que ello ocurre realmente. Con tal de mantener un trabajo que le es indispensable, el trabajador no tiene más alternativa que aceptar muchas veces la renuncia de un derecho que, en la letra de la ley, aparece como irrenunciable, cuestión que nos hace buscar el origen del problema, una vez más, en la solidaridad y conciencia de las personas involucradas (en donde incluyo también al trabajador, pues llegado el caso solo él sabrá si el trabajo que debe desempeñar está "bien hecho" o no).

\section{E) Las sillas en los establecimientos comerciales e industriales}

A tal extremo debió llegar el menosprecio por el trabajo y su elemento primordial, el trabajador, que la ley debió regular incluso una cuestión que, mirada desde la perspectiva de la dignidad mínima de la persona que trabaja, nos parece evidente.

En este sentido, entonces, el legislador debió exigir, coercitivamente, que en los establecimientos de comercio, los patrones o empresarios deben mantener el número suficiente de sillas o asientos, a disposición de su personal. Esta regla se hizo aplicable a los establecimientos industriales y a los obreros del comercio, cuando la naturaleza de las tareas desempeñadas lo ameritaran.

Para el cumplimiento de esta básica obligación (pues, aunque parezca difícil de creer, muchas veces no se cumple), la ley encomendó inicialmente su fiscalización a Carabineros y a los inspectores municipales, sin perjuicio de las facultades de la Inspección del Trabajo.

Hoy en día, esta obligación se encuentra expresamente consagrada en el artículo 193 del Código del Trabajo. Esta sola circunstancia nos debe llevar a reflexionar. Si el legislador, después de varias décadas, se ha visto en la necesidad de "mantener" una obligación que, mirada como un deber cristiano mínimo para con el trabajador, nos parece obvia, es 
precisamente porque la experiencia demuestra que ni siquiera ese deber -más moral que legal- se cumple voluntariamente. Muy poco ha avanzado entonces la conciencia social, en lo que al respeto de la dignidad de la persona del trabajador respecta.

\section{F) El peso de los sacos de carguío por fuerza de hombre}

A esta materia se refería el Título VI del Libro II del Código del Trabajo de 1931. El artículo 339 disponía que el peso de los sacos que contengan cualquiera clase de productos o mercadería destinadas al carguío por fuerza del hombre, no podía exceder de $80 \mathrm{~kg}$ en total. Los sacos de trigo o cemento podían pesar, como máximo, $86 \mathrm{~kg}$. Asimismo, los sacos de procedencia extranjera solo podían ser transportados al hombro, si se rebajaba su peso a $80 \mathrm{~kg}$, siendo de cuenta de sus propietarios los gastos de esa operación. Por último, toda movilización de sacos con peso superior al legal, debía efectuarse por medios mecánicos, aceptados por la autoridad competente.

Esta regulación, que nos parece también evidente si la miramos en el ámbito de la dignidad del trabajador, ha debido ser mantenida también a lo largo de las décadas. Hoy, se encuentra expresamente contemplada en el artículo 187 del Código de Trabajo, cuestión que nos confirma lo expresado en el acápite anterior.

\section{Conclusiones}

Hemos visto que, ya a partir de fines del siglo XIX, la legislación laboral de nuestro país ha mostrado una importante evolución en lo que al reconocimiento de la dignidad de la persona del trabajador respecta. Muchas y muy nobles han sido las iniciativas emprendidas por los distintos gobiernos a lo largo de este siglo, plasmadas en una legislación que busca evitar, en último término, el arraigado desprecio que ha existido -hoy en menor medida- por el trabajo, el sujeto del mismo y las condiciones en que vive.

Sin embargo, no es entonces el número de leyes (y hemos visto que son muchas) lo que soluciona el problema de fondo -que aun permanece-, por bien intencionadas y acertadas que ellas sean. Una y otra vez, ninguna solución legislativa podrá reemplazar o corregir los defectos de la conciencia de cada cual, al momento de analizar el verdadero valor que Dios le dio al trabajo desde la creación misma, al sentenciar: "Con el sudor de tu frente comerás el pan"8.

8 Génesis, 3,19. 


\section{Bibliografía}

- Arias, José F.: Medicina Social, Medicina del Trabajo, Edit. Montevideo, 1949.

- De la Cueva, Mario: Derecho Mexicano del Trabajo, Ed. Porrúa, México, T. II., 1961.

- Decreto $N^{\circ} 285$ del Ministerio del Trabajo y Previsión Social, publicado en el D. Of, de 26 de febrero de 1969, aprobó el estatuto orgánico de las Mutualidades de Empleadores, a que se refirió la Ley $\mathrm{N}^{\circ} 16.744$.

- Fermandois, Francisco Javier: Régimen Legal del Trabajo en Chile, Edit. Nacimiento, T. II., 1965.

- Krotoschin, Ernesto: Tratado Práctico de Derecho del Trabajo, Ed. Depalma, Buenos Aires, T. I., 1955.

- S.S. JuAn PABlo II: Laborem Exercens. Carta encíclica sobre el trabajo bumano, San Pablo, 2000. 